\title{
Voltage Dips Test System According to IEC 61000-4-11
}

\author{
J. M. Flores-Arias, F. Domingo-Perez, A. Moreno-Munoz, J. J. G. De La Rosa, and V. Pallares
}

\begin{abstract}
Voltage dips analysis is a complex stochastic issue, since it involves a large variety of random factors, such as: type of short-circuits in the power system, location of faults, protective system performance and atmospheric discharges. Among all categories of electrical disturbances, the voltage dips (sags) and momentary interruptions are the nemeses of the automated industrial process. This paper describes a system for voltage dips testing according to IEC 61000-4-11 norm. The system equipment is described also with the test process. Results are represented in power acceptability curves such as the Computer Business Equipment Manufacturing Association (CBEMA) curve and the Information Technology Industry Council (ITIC) curve.
\end{abstract}

Index Terms-Power acceptability curves, power quality, voltage dip or sag, voltage dips test.

\section{INTRODUCTION}

As more and more electronic equipment enter the residential and business environment, the subjects related to Power Quality (PQ) and its relationship to vulnerability of installations is becoming an increasing concern to the users. The two main aspects of PQ are [1]:

- Technical PQ, which includes: Continuity of supply or reliability (sustained interruption) and Voltage Quality (VQ), that are voltage level variations and voltage disturbances.

- Commercial services associated to the wires are regulated (such as the delay to get connected to the grid, etc.) as well as commercial services for energy retail to regulated customers.

Sustained interruptions, which occur when voltage falls to zero for more than a minute, are the reliability problem with which more electricity consumers have the greatest direct experience and are the key phenomena measured in traditional utility service quality and reliability statistics. Indices such as System Average Interruption Frequency Index (SAIFI) and Customer Average Interruption Duration Index respectively (CAIDI) do not capture PQ perturbations.

Power Quality is concerned with deviations of the voltage or current from the ideal single-frequency sine wave of constant amplitude and frequency. Poor PQ is a concern because it wastes energy, reduces electrical capacity, and can harm equipment and the electrical distribution system itself. Power quality deterioration is due to transient disturbances

Manuscript received October 14, 2012; revised November 29, 2012.

J. M. Flores-Arias, F. Domingo-Perez, A. Moreno, and V. Pallares are with the Comp. Arch., Electronics and Electronic Technology Department, University of Cordoba, Cordoba, ES-14017 Spain (e-mail: jmflores@ uco.es; p62dopef@uco.es; amoreno@uco.es; el1palov@uco.es).

J. J. G. De La Rosa is with the I.S.A., T.E. y E. Department, University of Cadiz, Algeciras (Cadiz), ES-11202 Spain (e-mail: juanjose.delarosa@uca.es). (voltage dips, voltage swells, impulses, etc.) and steady state disturbances (harmonic distortion, unbalance, flickers) [2].

The quality of the power supply delivered by utilities varies considerably and depends on a number of external factors. Things like lightning, industrial premises which apply and remove large loads, non-lineal load stresses, inadequate or incorrect wiring and grounding or short circuits caused by animals, branches, vehicular impact and human accidents involving electric lines.

With the generalized use of PLCs, adjustable-speed drives (ASDs), computers and other susceptible devices, the subject related to power quality and its relationship to vulnerability of highly automated plants is becoming an increasing concern to the industry. Among all categories of electrical disturbances, the voltage dips (sags) and momentary interruptions are the nemeses of the automated industrial processes.

Voltage dip is commonly defined as any low voltage event between $10 \%$ and $90 \%$ of the nominal RMS voltage lasting between 0.5 and 60 cycles. On the other hand, voltage swells (which are not so common) do not normally disrupt sensitive load, but can cause harm to equipment. Momentary voltage interruption is any low-voltage event of less than 10 percent of the nominal RMS voltage lasting between 0.5 cycles and 3 seconds. Voltage dips can be caused by natural events (e.g., trees falling on power lines or lightning striking lines or transformers), utility activities (e.g., routine switching operations or human error) or customer activities. Voltage dips at a customer bus are different depending to his location in the electrical network. Because of the short duration of these PQ events, residential customers are rarely aware that a VQ event has taken place. However, for many industrial customers, they pose a far more significant problem than outages because of their much greater frequency of occurrence and overall because of that their incidence can cause hours of manufacturing downtime.

In medium voltage distribution networks, voltage sags are mainly caused by power system faults. Fault occurrences elsewhere can generate voltage sags affecting consumers differently according to their location in the electrical network. Even though the load current is small compared to the fault current, the changes in load current during and after the fault strongly influence the voltage at the equipment terminals. It has been discovered that the $85 \%$ of power supply malfunctions attributed to poor Power Quality are caused by voltage dip or interruptions of fewer than one second duration [3]-[6].

Starting large motors can also generate voltage dips, although usually not so severe. In comparison with interruptions, voltage dips affect a larger number of customers and for some customers voltage sags may cause extremely serious problems. Some major problems 
associated with unregulated line voltages (in particular, long-term voltage dips) include equipment tripping, stalling overheating and complete shutdowns of sensitive equipment if it is designed to operate within narrow voltage limits, or it does not have adequate ride-through capabilities to filter out fluctuations in the electrical supply. These subsequently lead to lower efficiencies, higher power demand, higher cost for power, electromagnetic interference to control circuits, excessive heating of cables and equipment, and increased risk of equipment damage. The need for line voltage regulation still remains a necessity to meet demands for high industrial productivity.

There are several conditioning solutions to voltage regulation, which are currently available in the market place. Among the most common are Un-interruptible Power Supply systems (UPS). Recently, new technologies like Custom power devices based on power electronics concepts have been developed to provide protection against PQ problems.

Instrumentation and control operations require high quality and ultra-reliable power in the quantities and time frames that have not been experienced before. It was estimated that dips below $87 \%$ voltage and greater than 8.3 $\mathrm{ms}$ in duration at the utility feed to the plant would likely disrupt production. However, nowadays the situation is worse, because more than $30 \%$ of the power currently being drawn from the utility companies is used for sensitive equipment, and this amount is growing up [5].

The IEC norm defines a voltage dip (or sag) as "a sudden reduction of the voltage at a particular point of an electricity supply system below a specified dip threshold follow by its recovery after a brief interval". The latest version of the IEC 61000-4-11 (second edition) dates from March 2004 and it is the only one which must be used since first of June 2007 [7].

This edition adds to the previous one a new dips level, whereas Edition 1 only used $0 \%, 40 \%$ and $70 \%$, Edition 2 adds the dips level $80 \%$. It also includes a definition of Equipment Under Test (EUT) classes, specifying test levels and durations.

A power acceptability curve is a kind of graph that plots the change of the supply voltage (usually in percent) versus its duration (in seconds or cycles). The CBEMA curve divides the graph in two regions, the acceptable power zone and the unacceptable zone, which is divided into overvoltage and undervoltage. Lower durations (below 8.33 milliseconds, a $60 \mathrm{~Hz}$ half-cycle) are considered acceptable for voltage dips. From about five seconds (steady state) is considered unacceptable a variation below $87 \%$. The construction of the CBEMA curve is discussed in [8].

The CBEMA curve was replaced by the ITIC curve at the end of 20th century, this curve differs from the other one in having straight lines instead of curves. It also has a narrower steady state tolerance, whereas CBEMA curve considered a voltage variation less than $87 \%$ as unacceptable the ITIC curve set the steady state limit in $90 \%$. Reference [9] explains every aspect of the ITIC curve.

\section{Methodology}

The voltage dips testing facility described next has the main purpose of being used for voltage dips testing in electronics ballast.

The test procedure is very similar to that given in [9], except from this is a test system for single-phase equipment and the use of power acceptability curves as the end of every measurement.

\section{A. Equipment}

The following items are used during the system development:

- A PC, in order to run the test software and store the measurement results.

- A two-channel USB oscilloscope.

- A voltage dips generator according to IEC 61000-4-11 Edition 1 controlled by an USB to serial adapter. It incorporates predefined tests for the first edition of the voltage dips test norm, but it also has the possibility of define new test durations and adapt the machine to new norm revisions.

- $\mathrm{AC} / \mathrm{DC}$ voltage converter Evaluation Modules (EVM) with resistive loads.

\section{B. Connection}

The oscilloscope and the voltage dips generator are connected to the PC via USB. The generator input is plugged to the main line and the output is used to supply power to the EVM. Resistive loads are attached to the DC output of the EVMs.

One scope channel measure the generator signal that indicates the moment when the dip is running, the other channel measure the output voltage from the EVM.

\section{Software}

The control of the scope and the generator has been integrated in one software module. Fig. 1 shows the aspect of the main program window. This first program version only uses the predefined test of IEC 61000-4-11 Edition 1 (Table I), this software is been improving in order to automate the new test levels and durations.

TABLE I: TEST LEVELS AND DURATIONS DESCRIBED BY

\begin{tabular}{cc}
\multicolumn{2}{c}{ IEC 61000-4-11 EDITION } \\
\hline \hline Dip level (\%) & Dip duration (periods) \\
\hline 0 & $0.5^{*}$ \\
& 1 \\
40 & 5 \\
& 10 \\
70 & 25 \\
& 50
\end{tabular}

$*_{\text {The half-cycle duration need to be tested for both positive and negative }}$ half-cycle

When the voltage dips test software is executed two windows appear. One of them is the main window and the other one is the representation of the ITIC and CBEMA curve (Fig. 1). The CBEMA curve is only represented by its undervoltage condition, as we are only studying voltage dips it does not mind the overvoltage curve.

The main window allows configuring the most representative parameters of the scope and selecting the voltage dips test (there is a label explaining all the tests up the test control button). Selecting a test number is only applied to its duration, the dip level must be set manually with a dial in 
the voltage dips generator.

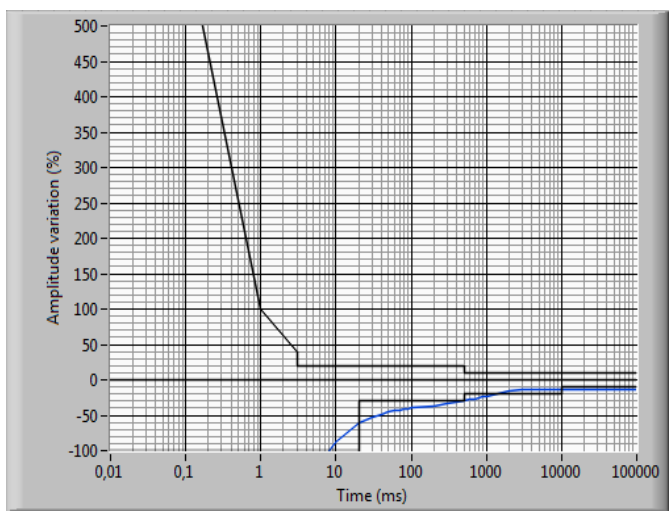

Fig. 1. ITIC and CBEMA (undervoltage condition) curves.

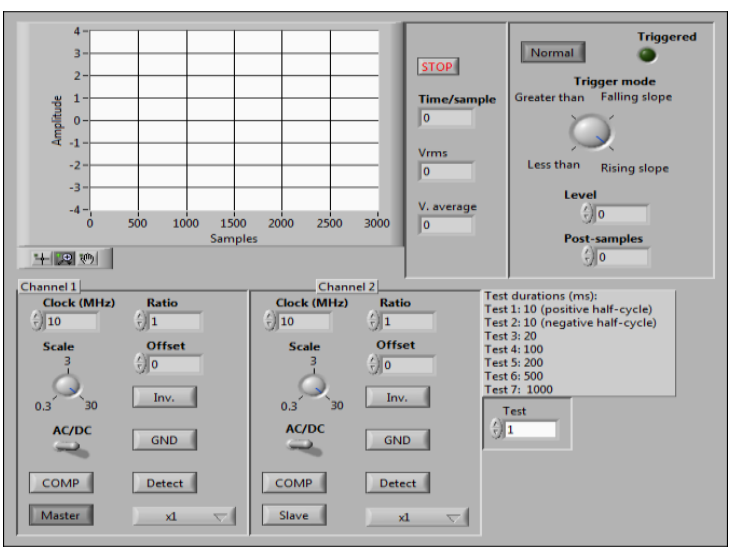

Fig. 2. Voltage dips test software main window.

Selected options in Fig. 2 are the default settings

Right the waveform graph there are three indicators representing the time per sample (the used scope can only get three thousand samples per measurement), the RMS voltage and the average voltage. During the test the RMS voltage is measured when the Evaluation Module (EVM) is working normally and at the end of the test, so the two parameters are taken to the CBEMA and ITIC plotting the RMS voltage variation, activating an alarm signal when the new point fall into the unacceptable zone of ITIC or CBEMA curves.

\section{Test Process}

First, the dip level must be selected by hand with the generator dial.

The scope is configure for triggering when channel 1 detects a rising slope, this signal come from the voltage dips generator and it is activated when the dip is running.

While the test is not running, the EVM is supplied by the main line, so it is working normally and the channel 2 is measuring the normal output voltage and storing it RMS and average value. Once the test starts channel 1 is triggered and the clock scope is configured covering the dip test duration so the entire voltage during the dip is measured and stored for later revisions. The RMS voltage previous to the first test is used to reckon the voltage variation with the RMS value obtained at the end of the test. When a test fail, the number of the test and its result is saved, so the data can be reviewed to consider the fail importance.

\section{TEST EXAMPLE}

In order to check the correct work of the new system developed two EVMs have been tested. Both of them have been executed with the following equipment:

- $\quad$ PC: Intel Pentium IV 1.6GHz, 384MB RAM, 40GB HDD, running Windows ${ }^{\circledR}$ XP SP2.

- USB oscilloscope: Elan Digital Systems USBScope $50 \AA$, 50 megasamples per second, 8 bits resolution, full scale of $300 \mathrm{mV}$ to $30 \mathrm{~V}$ with $1 \mathrm{x}$ probe.

- Voltage dips generator: Deneb Elettronica DNBGVD01®, max current to load of $5 \mathrm{~A}$ and a dip rise time of 1 to 5 microseconds.

- The software is been developed using National Instrument LabVIEW ${ }^{\mathrm{TM}}$ 7.1.

The first test was developed under the following conditions:

- EVM: Texas Instrument UCC28514EVM, AC/DC voltage converter with Power Factor Correction (PFC), designed to operate over an universal input range of $85 \mathrm{~V}$ to $265 \mathrm{~V}$ with a regulated $24 \mathrm{~V}, 100 \mathrm{~W}$ output. The used load is a parallel resistor combination of two $15 \Omega / / 50 \mathrm{~W}$.

- Test 1: $0 \%$ dip level, $0.5 \mathrm{~ms}$ (positive half-cycle).

- Test 2: 0\% dip level, $0.5 \mathrm{~ms}$ (negative half-cycle).

- $\quad$ Test 3: 40\% dip level, 200ms.

- Test 4: 70\% dip level, 1000ms.

- Every test has been repeated a minimum of three times with ten seconds between dips.

Fig. 3 and Fig. 4 represent the measured waveform and the four tests in the power acceptability curves. As the EVM accept a wide voltage range and it is designed to pass the Electromagnetic Compatibility (EMC) tests the output voltage does not change.

The scope uses an 8 bits ADC, in order to measure $24 \mathrm{~V}$ we use the $30 \mathrm{~V}$ scale, this way we have got an accuracy of $0.236 \mathrm{~V}$, by entering the measured signal into a median filter we can get the Fig. 3 waveform.

The second test is similar to the first one, changing the EVM, all the parameters about durations, levels, etc. are still the same. The new EVM is following described:

- Texas Instrument UCC28019EVM, a PFC boost converter that accommodates an input voltage of 85 to $265 \mathrm{VAC}$ and provides a 390 regulated output at $0.9 \mathrm{~A}$ of load current. The resistive load is a combination of two serial resistors of $1 \mathrm{k} \Omega / 50 \mathrm{~W}$.

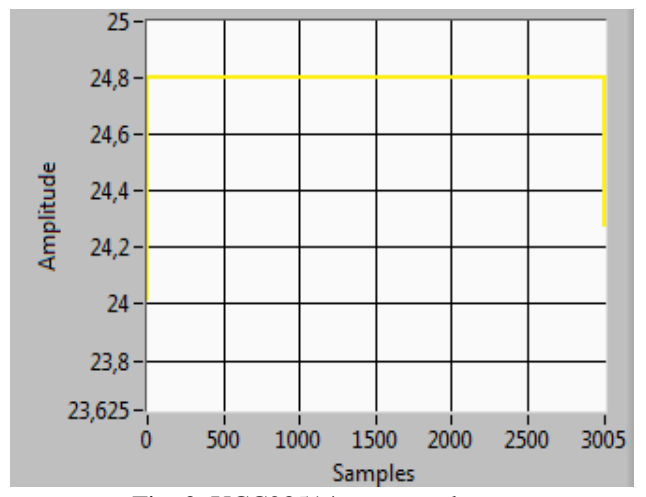

Fig. 3. UCC28514 output voltage. 


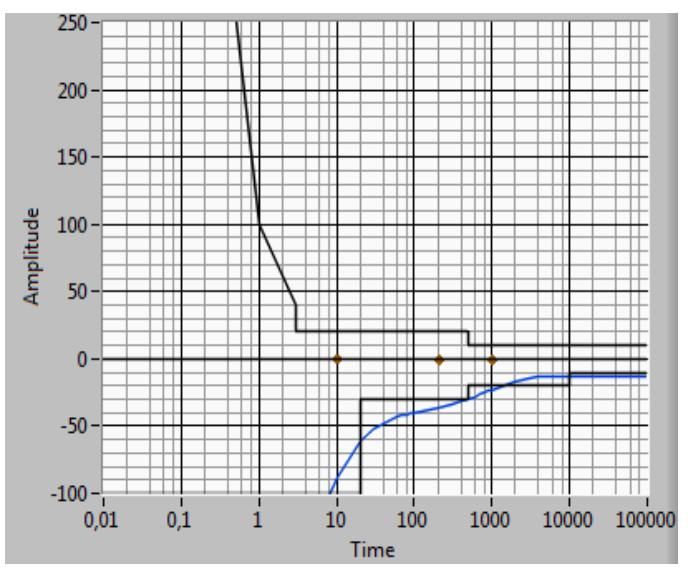

Fig. 4. UCC28514EVM test results.

The measurement of voltages greater than $300 \mathrm{~V}$ requires an $\mathrm{x} 100$ probe, then we get a $3000 \mathrm{~V}$ full scale with a resolution of 8 bits, hence the accuracy is multiplied by ten, so the new accuracy is $23.6 \mathrm{~V}$, Fig. 5 shows this big voltage absolute error.

Fig. 6 represents again the voltage variation in the power acceptability curves, this EVM was developed according to EMC norm and it has a wide voltage range so the results are the same that test first, there is no voltage variation and the test is passed.

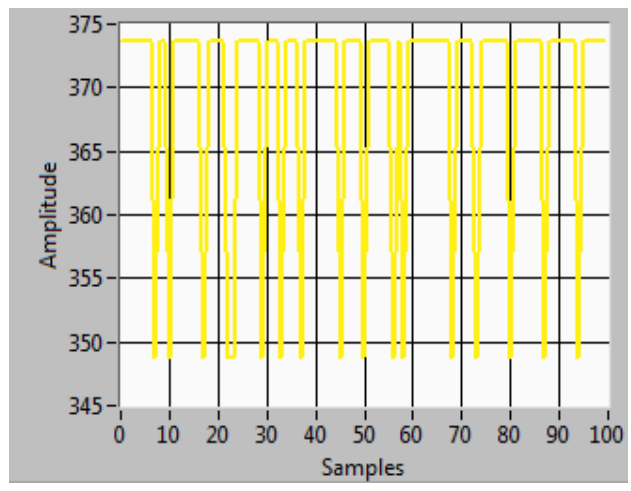

Fig. 5. UCC28019 390V voltage output measured with an 8 bits resolution oscilloscope UCC28514 output voltage.

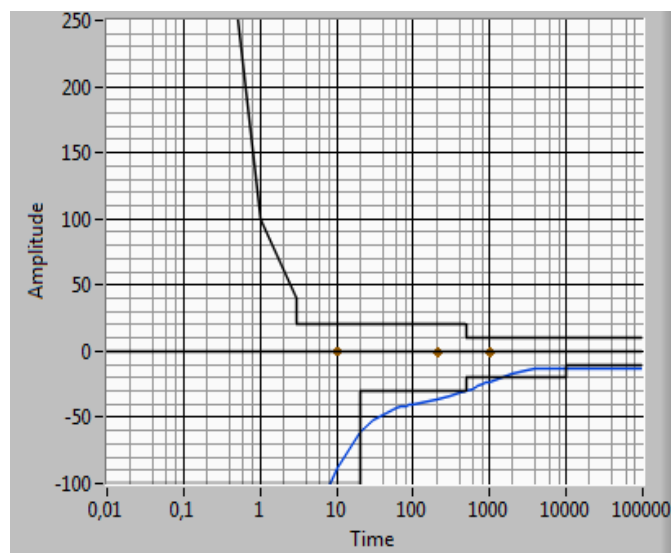

Fig. 6. UCC28019EVM test results.

\section{CONCLUSIONS}

The developed system can be used to test equipment according to IEC 61000-4-11 Edition 1, the implemented software for the voltage dips generator allows the user to define any dip duration between 10 and 2500ms. Because of this reason there is no problem in adapting the software to new norm revisions.

The next step to improve the voltage dips test system should be the possibility of changing the dip level by computer instead of turning the dial by hand, this will allow the user not to be present during the test execution for changing the dip level.

That way, the system is only limited due to the hardware specification. The low oscilloscope resolution makes very inaccurate any measurement above $300 \mathrm{~V}$. On the other hand, the voltage dip generator configuration is limited to changing the dip level and duration and the pause between dips, but the norm also advices about critical phase angles which should also be tested.

\section{ACKNOWLEDGMENT}

This research was supported partially by the Company Telvent Energy, Spain, through the project Malaga SmartCity under contract number 12009028. SmartCity's budget is partly financed by the European regional development fund (ERDF) with backing from the Junta de Andalucía and the Ministry of Science and Innovation's Centre for the Development of Industrial Technology. The authors would like to thank the Spanish Ministry of Industry, Tourism and Trade for funding the Project TSI-020100-2010-484 which partially supports this work. Our unforgettable thanks to the Spanish Ministry of Science and Innovation for funding the research project TEC2010-19242-C03-02.

\section{REFERENCES}

[1] D. L. Rosa, J. J. G. Moreno Muñoz, A. Gil de castro, A. Pallarés, V. Sanchez Castillejo, and J. A., "A web based distributed measurement system for electrical power quality assessment," Measurement Journal of the International Measurement Confederation, vol. 43, no. 6, pp. 771-780, 2010.

[2] G. D. Castro, A. Moreno-Munoz, A. De La Rosa, and J. J. G., "Characterizing the harmonic attenuation effect of high-pressure sodium lamps," 14th International Conference on Harmonics and Quality of Power (ICHQP), pp.1-6, 26-29 Sept. 2010.

[3] A. G. de Castro, A. Moreno Muñoz, V. Pallarés, D. L. Rosa, and J. J. G., "Improving Power Quality Inmunity in Factory Automation," Power Electronics Technology, vol. 35, no. 5, pp. 28-32, 2009

[4] A. Moreno Muñoz, D. L. Rosa, and J. J. G., "Voltage sag in highly automated factories," IEEE Industry Application Society Annual Meeting, art. no. 4659120, 2008.

[5] M. Muñoz and $M^{a}$ D. Redel, "Calm in the campus: power disturbances threathen university life,” IEEE Power Engineer, vol. 19, no. 4, pp. 34-37, August 2005.

[6] H. EMC Technology. Application Note: Dips and Interrupt Testings according to IEC 61000-4-11 Edition 2. [Online]. Available: http://Www.Haefelyemc.Com/.

[7] J. Kyei, R. Ayyanar, G. Heydt, R. Thallam, and J. Blevins, "The design of power acceptability curves," IEEE Transaction on Power Delivery, vol. 7, no. 3, pp. 828-833, July 2002.

[8] Information Technology Industry Council (ITI), ITI (CBEMA) curve application note, October 2000.

[9] A. K. Keus, J. M. Van Coller, and R. G. Koch, "A test facility for determining the response of industrial equipment to voltage dips (sags)," Electric Machines and Drives, 1999. International Conference IEMD, pp. 210, May 1999. 


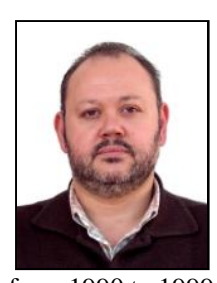

Jose-Maria Flores-Arias received his degree on Industrial Electronics Engineering (1990) and his M.Sc. degree in Automatics and Electronic Engineering (2000), from the University of Cordoba and actually he is a Ph.D.c. in the R\&D Group 'Computational Instrumentation and Industrial Electronics: PAI-TIC168' at the same University. He worked as R\&D and Maintenance Engineer for several companies from 1990 to 1999. Actually he is an Assistant Professor at the Comp. Arch., Electronics and Electronic Technology Department, University of Cordoba, since 2000.

Prof. Flores-Arias is a member in both IEEE Industrial Electronics and Consumer Electronics Societies since 2011. His research interest areas are Power Quality and Power Converters for Lighting and Smart Grids. He is author and co-author of several Scientific Papers and he is an active reviewer for IEEE EDUCON Conference and several journals focused on Power Electronics.

Francisco Domingo-Perez was born in Cordoba, Spain, in 1988. He is a Ph.D. student at University of Cordoba. He received the B.Sc. and M.Sc. degrees in Industrial Electronics in 2009 and 2011 from the University of Cordoba.

Antonio Moreno-Munoz is a full professor at the Department of Computer Science and Electronics Engineering, Universidad de Córdoba, Spain; where and he is Chair of the Industrial Electronics and Smart Grids R\&D Group. Nowadays he is the head of the Department. Dr. Moreno-Munoz received his Ph.D. and M.Sc. degrees from UNED "Universidad Nacional de Educación a Distancia", Spain in 1998 and 1992.

From 1981 to 1992 he was with RENFE, the Spanish National Railways Company. Since 1992 he has been with Universidad de Córdoba. He is: Director of Master of Distributed Renewable Energy at the University of Córdoba mainly focused on Smart Grids. R\&D projects Auditor for European Quality Assurance Ltd. (EQA), Springer Science publishing consultant, Reviewer focused in Smart Grids and Distributed Generation for IEEE, IET and Elsevier Journals (IET Generation, Transmission \& Distribution, IEEE Transactions on Power Delivery, IEEE Transactions on Industrial Electronics, IEEE Industrial Electronics Magazine, Applied energy, Energy and Buildings).

Dr. Moreno-Muñoz is an active researcher focused on Smart Grids, Power Quality, Electronic Instrumentation, and usability of complex systems, participating in 6 National R\&D projects since 2003. He has authored 3 monographs; 1 Hand-book for engineer and students; 85 Scientific Articles in Journals and Conference Proceedings or Records: conference Papers (62), articles (21) and reviews (2). Recently he has been General Co-Chair of the 3rd International ICST Conference on IT Revolutions 2011 23-25 March 2011 Cordoba, Spain

Juan José González de la Rosa received the M.S. degree in Physics-Electronics in 1992, from the University of Granada, Spain, and his Ph.D. in Industrial Engineering in 1999 (summa cum laude), from the University of Cádiz, Spain. Actually, he is an Associate Professor (Professor) and Researcher at the Electronics Area-Cádiz University (joined in 1995). Two awards-recognitions of six-year research periods (1999-2004 2005-2010) in the field of Engineering and Communication Engineering, Computation and Electronics by the National Assessment Commission of the Research Activity of the Spanish Ministry of Education and Science (CNEAI).

He is the author of a number of JCR research articles, attendant of multiple conferences and international research meetings, which are the result of his participation and leadership in research projects. He has also visited and attended Universities (invited professor), Research Institutes and Companies in France, Switzerland, Italy and Spain.

Dr. G. de la Rosa is one of the main researhers of the Spanish Research Group in Computational Instrumentation and Industrial Electronics. His research line is the Computational Intelligence for Enhancing Measurement Systems and Applications. As a consequence, he belongs to the IEEE Instrumentation and Measurement Society.

Víctor Pallarés-López is a full professor at the Department of C. Arq., Electronics and Electronics Technology, Universidad de Córdoba, Spain.

His specialty as teacher is the instrumentation and the signals processing. His main research activity is in the field of distributed measurement systems, with particular attention to the development of synchronization techniques suited to the monitoring applications in distribution networks.

Prof. Pallarés is a member of IEEE since 2009. His most recent works are related to the implementation of embedded systems for the detection and processing of disturbances in the electrical grid. These jobs are related to several research projects granted to the group and are in progress. This work has led to several publications and international conference contributions. 